\title{
Comparative Evaluation of Concentric Bracing Systems for Lateral Loads on Medium Rise Steel Building Structures
}

\author{
Sisaynew Tesfaw Admassu \\ ${ }^{*}$ Civil Engineering Department, Woldia University, Woldia, Amhara, Ethiopia
}

\author{
Article Info \\ Volume 7, Issue 4 \\ Page Number : 124-130 \\ Publication Issue : \\ July-August-2020
}

\section{Article History}

Accepted : 20 July 2020

Published : 30 July 2020

\section{ABSTRACT}

To resistance, the lateral load from wind or an earthquake is that the reason for the evolution of varied structural systems. Because, when a medium or any multi-level structure is exposed to horizontal or torsional deflections under the action of seismic burdens. Lateral stiffness is a major consideration in the design of the buildings. In addition to this, many existing steel buildings and reinforced concrete buildings for which the weak lateral stiffness is the main problem; should be retrofitted to conquer the insufficiencies to resist the lateral loading. Lateral load resisting systems are structural elements providing basic lateral strength and stiffness, without which the structure would be laterally unstable. The unstable nature of the structure is solved by the fitting arrangement of bracings systems. A bracing system is that forms an integral part of the frame. Thus, such a structure has to be analyzed before arriving at the best type or effective arrangement of bracing. Bracing is a highly effective strategy of resisting lateral forces in a frame structure. In this document, a tenstory building with incorporated bracing systems is analysed using ETABS 2016 analysis software as per Eurocode and Ethiopian Building Code Standards (EBCS). Then, the lateral displacement is evaluated under each of the bracing types.

Keywords: Bracing System, Concentric Bracing, Lateral Story Displacement, Storey Drifty

\section{INTRODUCTION}

When a medium and high-rise building is exposed to lateral or torsion deflections under the activity of fluctuating seismic burden or loads; the subsequent oscillatory movement can induce a wide scope of responses in the building's occupants from mild discomfort to acute nausea. As far as the ultimate limit state is concerned, lateral deflections must be limited to prevent $2^{\text {nd }}$ order $\mathrm{p}$-delta effect due to gravity loading being of such a magnitude which may be adequate to precipitate collapse. To fulfill strength and serviceability limit states, lateral stiffness is a significant thought in the design of medium and highrise buildings. Different structural forms of medium rise buildings can be utilized to improve the lateral 
stiffness and to reduce the drift index. In this research, study is conducted for concentric braced frame structure in which bracing is a highly efficient to laterally stiffen the frame structures against wind load and earth quake load. The proficiency of the bracing is due to the diagonals work in axial stress. A bracing system is a structural system which is designed essentially to resist seismic loads. Steel bracing is one of such system which is economical, easy to erect, consumes less space and has flexibility to design for meeting the required quality/strength and stiffness. It is usually placed in vertically aligned spans.

\section{A. Concentrically Braced Frames}

These are the kind of bracings whose centroidal axis corresponds with each other. They basically increment the horizontal stiffness of the frame which in turn increases the natural frequency and also decreases the lateral storey displacement. However, increment in the stiffness may attract a larger inertia force due to earthquake force. Further, the bracing increases the axial compression in the columns to which they are connected by decreasing the bending moments and shear forces in the column. And if, the bracings are omitted the bending moments and shear forces in columns increment but the axial compression in the columns to which they are connected is decreased. In the case of concrete building since reinforced concrete columns are strong in compression, it may not pose a problem to retrofit in reinforced concrete frame using concentric steel bracings.

CBFs have suitable lateral stiffness to prevent relative drift due to lateral load impacts resulting from earthquake. Such braces are part of relatively stiff systems and compatible with common needs of architecture with varied forms as shown (Fig 1). And also concentrically braced frames can be arranged in different forms such as cross, diametric V-shape, Chevron (inverted-V), K shape, etc. Those types of braces have not any link length between the connection points of bracing and beams that differs from eccentrically bracing type. It is a common phenomenon to use either steel or concrete materials for structural bracings as a lateral load resisting mechanism in areas of high seismic zonal regions. Or it can be also used shear walls either at the periphery of the buildings or at the locations of lift as a core structure.

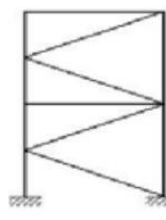

K-bracing

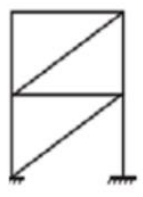

Diagonal bracin

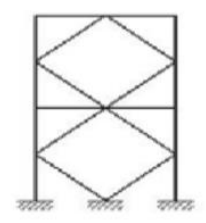

Comb. of $\mathrm{V}$ and Chevron bracing

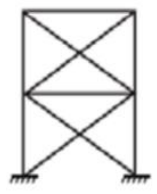

X-bracing

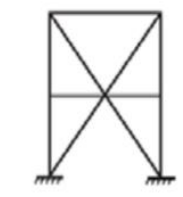

Multistory X-bracing

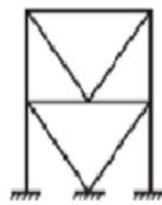

V-bracing

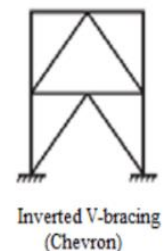

(Chevron)
Fig 1 Different types of CBFs

Generally, the use of steel concentrically bracing systems instead of Shear walls provides lower stiffness and resistance for a structure but it should not be forgotten that such a system has lower weight and more useful for architectural purposes.

For this paper emphasis is given for concentrically type of steel bracing having four different types of geometrical arrangements with similar cross section for comparison purpose. Different researcherse workout comparisons of the efficiencies of different forms of bracings, but their criteria of making assumptions for the selected group are not similar. Most Comparison of bracing was made by taking shape as the only criteria [1].

Braced frames and moment frames are the most widely utilized framing systems for steel construction in seismic zones. Contrasted to a moment frame, a braced frame offers high-lateral stiffness for drift 
control. In a concentrically braced frame, the elements (beams, columns and braces) with the centrelines meeting at a joint structure a vertical truss framework. Members in concentrically braced frames are subjected essentially to axial loads in the elastic range. The diagonal bracing members are designed to deform in elastically during a moderate or severe earthquake.

$\mathrm{V}$ or inverted $-\mathrm{V}$ bracing is a popular configuration in the United States [2]. Because one brace in a story is expected to buckle and lose a significant amount of compressive strength while the other brace is expected to yield during tension, the AISC Seismic Provisions require that for SCBFs the beam be designed for an unbalanced vertical load at mid span. It has been suggested that the adverse effect of this unbalanced load be mitigated by using bracing configurations such as $\mathrm{V}$ and inverted- $\mathrm{V}$ braces in alternate stories to create an $\mathrm{X}$-configuration over two-story modules.

The worldwide design objective for energy dissipation in the case of CBFs is to form dissipative zones in the diagonals under tension, and to avoid yielding or buckling of the beams or columns. Diagonals in compression are designed to buckle. The expected behaviour for global mechanism in the case of a frame with chevron bracing (inverted $\mathrm{V}$ bracing) is shown in Fig 2. In this case, when the compression brace buckles,

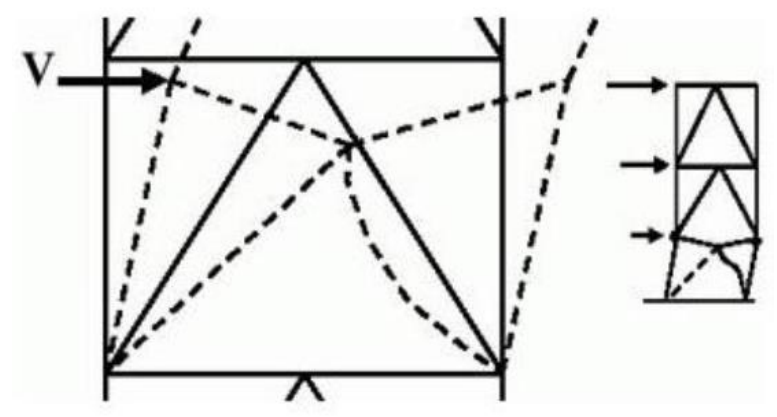

Fig 2 Chevron Brace Buckling tension braces force doubles (before buckling has fifty percent of $\mathrm{V}$ in the tension brace and fifty percent of $\mathrm{V}$ in the compression brace). The vertical component of the tension brace axial force becomes a point load on the beam, pulling the beam down and possibly leading to hinging and buckling of the brace frame column.

When chevron/inverted V bracing is used, the beam must be designed for an unbalanced load when the compression brace buckles. Often the resulting brace frame beam design weighing more. By correlation, when a two-storey $\mathrm{X}$ brace is utilized, when the compression brace buckles at the first floor, the braces at the second floor prevents the brace frame beam from buckling and designing the beam for an unbalanced loading is not necessary [3].

\section{B. Performance of Concentrically Braced Frames}

The design of a multi-story steel building under lateral loads is usually governed by system performance criteria (overall stiffness) rather than by component performance criteria (strength). An important task in the design of a tall steel building for structural designers is to select cost-efficient lateral load resisting systems. Pure rigid frame systems alone are not effective in resisting horizontal loads for medium and high-rise steel buildings due to associated significant expenses. Truss members such as diagonals are often used to brace steel frameworks to maintain horizontal drifts within acceptable limits. In the absence of an efficient optimization technique, the selection of lateral bracing systems for multi-story steel frameworks is usually undertaken by the designer based on a trial and error process and previous experience. The optimal layout design of bracing systems is a challenging task for structural designers because it involves a large number of possibilities for the arrangement of bracing systems. 
System performance is strongly influenced by aspects of brace behaviour (Lehman et al. 2008). As Lehman proved in his experiment, Brace buckling places large inelastic demands on the brace at the middle of the brace, typically resulting in a plastic hinge at midspan. Brace buckling also places significant demands on gusset plate connections and adjacent framing members. Limited cracking of the welds joining the gusset plate to the beams and columns generally is expected because of gusset plate deformation. These cracks normally initiate at story drifts in the range of $1.5 \%$ to $2.0 \%$, but the cracks remain stable if the welds meet size and demand-critical weld requirements. [4].

Concentrically braced frames are also strong, stiff and ductile, making them ideal for seismic framing structures. The inelastic behaviour of the brace provides most of the ductility, but in order to fully utilize the frame, the Connections and framing members must also be considerable. Therefore, it is important to consider not only the performance of the brace when designing, but also the ability for the connections and the framing members to withstand the strength and deformation demands transferred from the brace during cyclic loading. Through these contemplations, a maximum amount of energy can be dispersed before the system fails. [5]

\section{MODELING AND LOADING}

For nonlinear analyses, a 3D rectangular shape steel building structure has been selected. The building considered for analysis is ten rectangular plan steel building in elevation on $12 \mathrm{mx} 12 \mathrm{~m}$ plan size. Columns are spaced at $4 \mathrm{~m}$ interval in both directions and its corresponding story height is $4 \mathrm{~m}$. It is also assumed that to support the deck slab secondary steel beam is provided with a spacing of one meter at each floor level. The bracing is assumed to be a channel section which is provided at the edge/periphery of the building at each floor level. The lateral seismic loads to be applied on the building are based on Ethiopian Building Code of Standards EBCS. The study is performed for seismic zone 4 in Debre Zeyit city as per the code provision and with basic wind speed of $22 \mathrm{~m} / \mathrm{s}$ as per the code provision. The frames are assumed to be firmly fixed and the soil structure interaction is neglected. The load combinations and other design parameters associated with the steel structure are as per EBCS 8.

In order to evaluate different bracing systems, prior to going into any action for assessment, models with different bracing systems must be considered. In this regard the types of selected models, their shape and sizes are significant as they have influence on the behaviour of the frame models. As a result, the frame geometry selected was identical both in $\mathrm{x}^{-}$and $\mathrm{y}^{-}$ coordinate system having a plan dimension of $12 \mathrm{~m}$ by $12 \mathrm{~m}$. Each bay has a $4 \mathrm{~m}$ by $4 \mathrm{~m}$ square shape element which consists of a secondary beam spaced in one meter is shown in Fig 3 below.

Beams and columns, are I steel sections and each bracing system has been analysed using channel section. For the simplification of the study the same sections have been used for all bracing systems. Depending on the number of storeys of the building, for all steel members nominal steel grade of Fe510 has been used. The building has been modelled using ETABS 2016 software package and then a linear static analysis has been performed on the same structure for both concentric and eccentric type of bracings. 


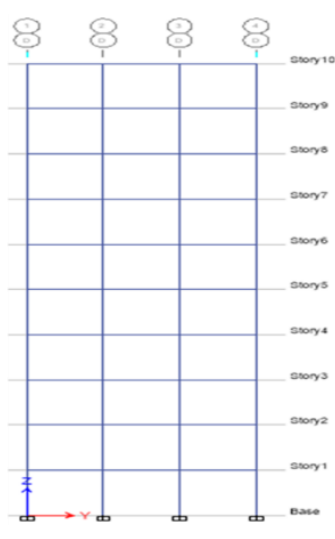

Fig 3 Layout plan of steel building and Unbraced Frame
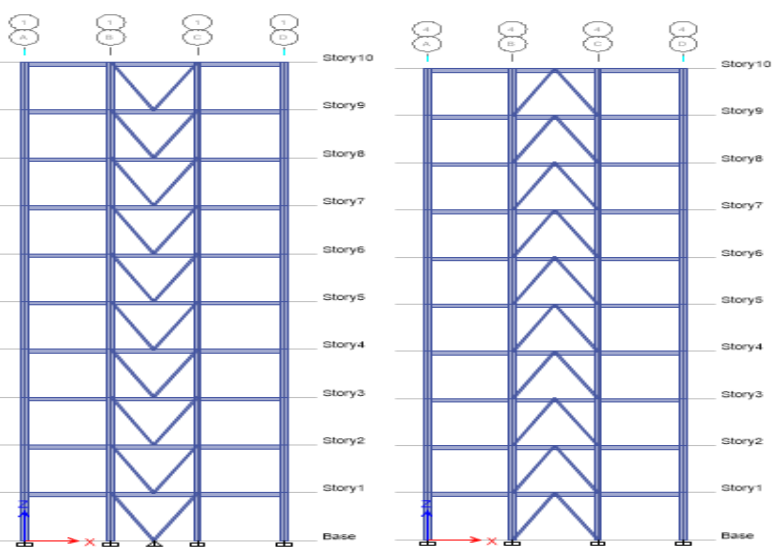

a) V Bracing system M 2 b) Inverted V Bracing System M 3
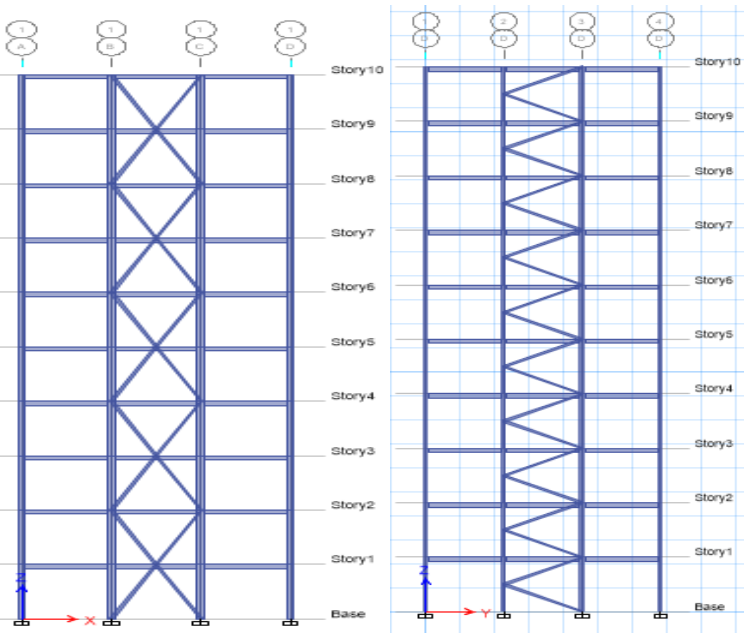

c) Comb Bracing system M 4

d) K- Bracing system

M 5

Figure 4 Concentrically Bracing systems

\section{A. Geometric Data}

Ethiopian Building Code of standards EBCS 8 suggests two different design spectrums: [6]

- Type 1 more seismically active zones (zone 4), and

- $\quad$ Type 2 less seismically active zones (zone 1and 2) In this study, According to EBCS 8 Type1 design spectrum is selected in order to notice the effect of earthquake on each bracing systems which may give maximum lateral displacement. In addition, there are also different parameters that are considered as an input for analysis. Of which behaviour factor ( $\mathrm{q}$ ) is one factor that affect the analysis result.

The beams, columns and bracings are an I-section steel element with their corresponding size is tabulated as follow:

TABLE I

GEOMETRIC DATA

\begin{tabular}{|l|l|}
\hline Type of structure & Steel bracing frame \\
\hline Number of stories & $\mathrm{G}+10$ \\
\hline Height of each story & $4 \mathrm{~m}$ \\
\hline Space of columns & $4 \mathrm{~m}$ \\
\hline Types of building & Industrial or commercial \\
\hline Seismic zone and location & 4 (Debre Zeyit), Ethiopia \\
\hline Basic wind speed & $22 \mathrm{~m} / \mathrm{s}$ \\
\hline
\end{tabular}

TABLE II DESIGN SECTIONS USED IN THE MODEL

\begin{tabular}{|c|c|c|}
\hline \multirow[t]{2}{*}{ Types } & \multicolumn{2}{|c|}{ Wide flange Design section } \\
\hline & $\mathrm{lbs} / \mathrm{ft}$ & $\mathrm{Kg} / \mathrm{m}$ \\
\hline Beams & W12x6.5x30 & W $310 \times 165 \times 44.5$ \\
\hline Columns & $\mathrm{W} 12 \times 12 \times 96$ & W $310 \times 310 \times 143$ \\
\hline Bracings & W5x5x16 & W $130 \times 130 \times 23.8$ \\
\hline $\begin{array}{l}\text { Secondary } \\
\text { Beam }\end{array}$ & W8x $4 \times 10$ & W $200 \times 100 \times 15.0$ \\
\hline
\end{tabular}

\section{B. Loading Consideration}

For analysis of this steel building, different loads are considered. These are self-weight of the structure, 
external wall load at the periphery of the building which is called cladding load, superimposed load from fixed furniture, live load, and earthquake loads are considered. These loads are taken by assuming the building is to produce similar service at each level of the floors systems. Because the main target of the study is to evaluate and identify the most effective types of bracing, from the given concentrically types of bracings. The building is subjected to the following loads as per Ethiopian Building Code Standard, EBCS 1 (Basis of design and Action on the structure).[7]

TABLE III LIVE AND DEAD LOAD DATA ACTING ON THE BUILDING ACCORDING TO EBCS1

\begin{tabular}{|l|l|}
\hline Density of brick wall & $20 \mathrm{KN} / \mathrm{m}^{3}$ \\
\hline Dead load on slab & $4 \mathrm{KN} / \mathrm{m}^{2}$ \\
\hline Live load on slab & $4 \mathrm{KN} / \mathrm{m}^{2}$ \\
\hline Thickness of wall & $0.2 \mathrm{~m}$ \\
\hline $\begin{array}{l}\text { Wall load on beams } \\
\text { (external wall load) }\end{array}$ & $12 \mathrm{KN} / \mathrm{m}$ \\
\hline Earthquake load & $\begin{array}{l}\text { As per the code } \\
\text { provision }\end{array}$ \\
\hline
\end{tabular}

\section{ANALYSIS AND RESULTS}

This steel building frame is subjected to the previously specified loads and the corresponding lateral displacement and story drift at each storey level for the particular bracing types observed. When the earthquake force applied to the building in the $\mathrm{X}$ direction some parametric result was found and presented in subsequent section shown below.
TABLE IV MAXIMUM NODAL DISPLACEMENT AT THE TOP STOREY IN X DIRECTION

\begin{tabular}{|l|l|}
\hline Model & Node displacement (mm) \\
\hline $\begin{array}{l}\text { Reference Model (Model } \\
\text { 1) }\end{array}$ & 165.076 \\
\hline Model 2 & 124.684 \\
\hline Model 3 & 117.612 \\
\hline Model 4 & 120.815 \\
\hline Model 5 & 113.029 \\
\hline
\end{tabular}

TABLE V REDUCTION IN DRIFT INDEX PERCENTAGE

\begin{tabular}{|l|l|l|l|}
\hline Model & $\begin{array}{l}\text { Node disp } \\
(\mathrm{mm})\end{array}$ & Drift & $\begin{array}{l}\text { Per. of red. } \\
(\%)\end{array}$ \\
\hline $\begin{array}{l}\text { Reference } \\
\text { (Model 1) }\end{array}$ & 165.076 & 0.003915 & \\
\hline Model 2 & 124.684 & 0.002275 & 24.47 \\
\hline Model 3 & 117.612 & 0.002143 & 28.75 \\
\hline Model 4 & 120.815 & 0.002194 & 26.81 \\
\hline Model 5 & 113.029 & 0.002988 & 31.53 \\
\hline
\end{tabular}

TABLE VI LATERAL DISPLACEMENT VALUES

\begin{tabular}{|l|l|l|l|l|l|}
\hline \multirow{2}{*}{$\begin{array}{c}\text { Store } \\
\mathbf{y}\end{array}$} & & $\mathbf{4}$ & \multicolumn{4}{|l|}{ Concentric Bracings } \\
\cline { 2 - 6 } & & $\mathbf{M} 2$ & $\mathbf{M}$ & $\mathbf{M} 4$ & $\mathbf{M} 5$ \\
\hline St10 & 165.07 & 124.68 & 117.6 & 120.81 & 113.02 \\
\hline St9 & 159.62 & 115.58 & 109.0 & 112.04 & 101.07 \\
\hline St8 & 150.47 & 104.60 & 98.51 & 101.24 & 87.97 \\
\hline St7 & 137.84 & 92.254 & 86.53 & 89.13 & 74.661 \\
\hline St6 & 122.17 & 78.757 & 73.38 & 75.807 & 60.663 \\
\hline St5 & 103.93 & 64.443 & 59.45 & 61.642 & 46.554 \\
\hline St4 & 83.592 & 49.718 & 45.22 & 47.295 & 33.336 \\
\hline St3 & 61.620 & 35.068 & 31.27 & 32.761 & 20.199 \\
\hline St2 & 38.579 & 21.054 & 18.26 & 19.561 & 10.675 \\
\hline St 1 & 15.661 & 8.316 & 6.945 & 7.002 & 1.491 \\
\hline
\end{tabular}




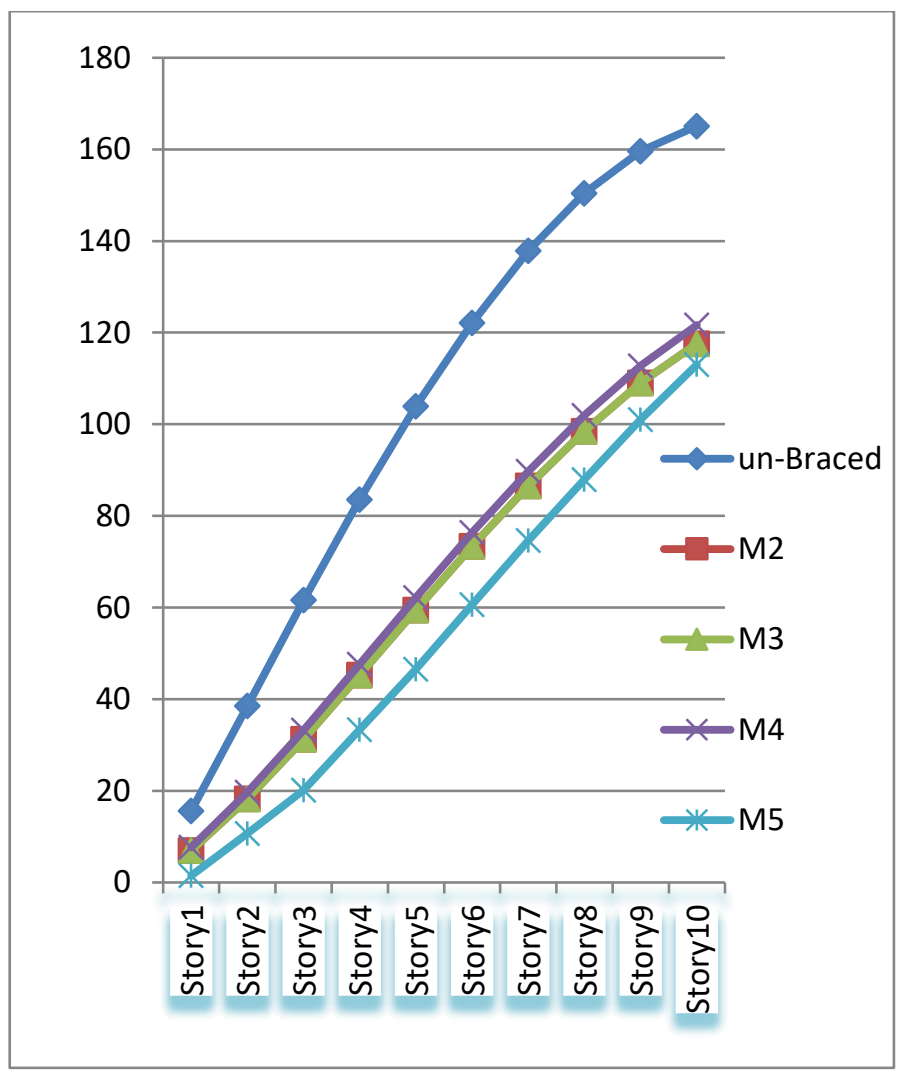

Fig 5 Plots of lateral displacement

\section{IV.CONCLUSION}

K type bracing (M5) has least nodal displacements with respect to storey height when compared to un-braced reference model and also have lesser values of horizontal displacement compared to other bracings. This indicates that it can give higher resistance mechanism for the overall building structure.

$>\mathrm{K}$ type bracing (M 5) has maximum reduction in drift index percentage of $31.53 \%$ in comparison with the un-braced reference model in the $\mathrm{X}$ direction.

$>$ For some bracing systems, the story drift values will increase from one story to the next storey then it reduces gradually for higher story levels.

From the four concentric and four eccentric types of bracings, $\mathrm{K}$ type bracing performs better.

\section{REFERENCES}

[1] Azar, Behruz Bagheri. "” Study the Effect of using Different Kind of Bracing System in Tall Steel Structures"." Euro-Journals Publishing, Inc., IRAN, 2012.

[2] M. N. Chimeh \& P. Homami. "” Efficiency of bracing systems for seismic rehabilitation of steel structures"." Kharazmi University, Tehran, 2012.

[3] Chia-Ming Uang. "“Steel Buckling-Restrained Braced Frames"." CRC Press LLC, 2004.

[4] Lehman, D.E., Roeder, C.W., Herman, D., Johnson, S., and Kotulka. "IImproved seismic performance of gusset plate connections,"." ASCE, Journal of Structural Engineering,Reston, VA, 2008: Vol. 134, No. 6.

[5] Canney, Nathan. "'Performance of concentrically braced frames under cyclic loading"." Seattle University, Washington, n.d.

[6] EBCS8 DESIGN OF STRUCTURES FOR EARTHQUAKE RESISTANCE, ADDIS ABABA, ETHIOPIA, 1995.

[7] EBCS-1 Ethiopian building code of standard for BASIS OF DESIGN AND ACTIONS, ADDIS ABABA, ETHIOPIA, 1995.

\section{Cite this article as :}

Sisaynew Tesfaw Admassu, "Comparative Evaluation of Concentric Bracing Systems for Lateral Loads on Medium Rise Steel Building Structures", International Journal of Scientific Research in Science and Technology (IJSRST), Online ISSN : 2395-602X, Print ISSN : 2395-6011, Volume 7 Issue 4, pp. 124-130, July-August 2020. Available at doi $\quad$ : https://doi.org/10.32628/IJSRST207428 Journal URL : http://ijsrst.com/IJSRST207428 